Journal for Social Action in Counseling and Psychology

Volume 3, Number $1 \quad$ Spring 2011

\title{
Continuing and Expanding the Multicultural Social Justice Leadership Conversation: An Introduction to the Special Issue of the Journal for Social Action in Counseling and Psychology on the 2010 Multicultural Social Justice Leadership Development Academy
}

\author{
Carlos P. Zalaquett \\ University of South Florida
}

\section{Brave and Viral Creativity}

This past spring 2010, Michael D'Andrea and I (Carlos) discussed the importance of the first Multicultural-Social Justice Leadership Development Academy (MSJLDA). This special event, to be conducted during the American Counseling Association's annual conference, in Pittsburgh, PA, was designed to promote understanding of multicultural-social justice leadership development and its applications. The day-long program included selected presentations organized to increase participants' knowledge about multicultural-social justice leadership, its development, and ways to effectively implement this leadership in a broad range of settings and populations. During this conversation, we envisioned ways in which to expand the narratives and conversations that were to be initiated at this seminal event. Our goal was to engage presenters and participants in a coconstructive dialogue during and after the Academy.

Soon thereafter Mark Kenney, co-chair of the Academy, Rebecca Toporek and Tod Sloan, editors of the Journal for Social Action in Counseling and Psychology, and Jessica Barrett, coordinator of the event, joined the conversation. We discussed different ways to involve the participants and to continue the dialogue after the Academy. Each one of our ideas shared a common purpose, to build a special journal issue to share different co-constructed narratives about how to develop multicultural, social justice leadership.

Our quest was to integrate the presenters' views with those of the participants, as well as to engage them in creating shared plans for action. Our goals for this Special Issue were to premier the outcomes of these conversations, highlight what was learned during the 2010 MSJLDA, and serve as a scaffolding foundation for future discussions. 
Journal for Social Action in Counseling and Psychology

Volume 3, Number $1 \quad$ Spring 2011

\section{A Novel Frame of Work}

Together we built the framework of what may be considered a novel social experiment in the construction of knowledge and practices of multicultural, social justice leadership. We did it based on our belief that teaching for multicultural, social justice leadership development should provide more than access to current knowledge and practices, it should provide opportunities to question, challenge, and reconstruct knowledge. Furthermore, multicultural social justice leadership pedagogy should offer possibilities for transformation not only of the participants, but also of the presenters. These, in turn, should collaborate in the transformation of the social and political contexts in which their education, training, and social actions occur; creating a viable, ever evolving conversation.

Also foundational for the development of the special issue was the fact that most topics addressed in these types of events are not resolved in one presentation. Usually, the presentation creates an opportunity to raise additional questions and concerns regarding the topic. Thus, the development of a special issue could expand what was presented by addressing these questions and concerns in outcome manuscripts. The produced manuscripts could serve as the basis for future conversations.

\section{A Collaborative Method}

We invited Academy presenters to submit an article based on their presentation. We also asked them to invite comments, questions, and constructive criticism from the audience. In addition, we developed a survey to gather participants' reactions, reflections, and suggestions for action, and volunteers helped collect audience's surveys. Comments, questions, and suggestion by the audience were compiled and provided to the presenters. All presenters were encouraged to integrate in their manuscripts the information, ideas, and action plans gathered during and after their presentations; as well as to include their responses to the questions and comments made by the audience.

Each article submitted was required to follow the JSACP journal guidelines, presented at http://jsacp.tumblr.com/guidelines, and was coded for masked peer review process. Members of JSACP's editorial board reviewed each manuscript. Only peer reviewed and accepted manuscripts were included in this special issue. Authors did not serve as reviewers.

\section{Importance of Continuing the Conversation}

The special issue continues the tradition established by the Multicultural-Social Justice Leadership Development Academy. Providing access to the content, practices, and narratives of multicultural, social justice leadership can help 


\section{Volume 3, Number $1 \quad$ Spring 2011}

counselors, educators, social workers, and psychologists develop rich repertoires of knowledge and practices. Through this conversation, they can empower themselves to promote change and build a more socially just world. Participants can use the contents or the special issue for personal and social transformation. They can also engage in public discourse and debate to create a fair and just democratic society.

In addition, the narratives for a multicultural, social justice leadership development can facilitate the implementation of ways to challenge the sociopolitical contexts in which we participate as educators and practitioners. In each of the manuscripts included in this issue, presenters addressed a variety of constituents and contexts where social justice leadership can and is making a difference. Thus, facilitating the teaching and learning of multicultural, social justice leadership that contributes to the development of a more just society for individuals, communities, states, and nations.

In this special issue you will find different types of articles, with diverse narratives, varying number of practical examples and suggestions for action, and different levels of theoretical references. These articles speak about the personal journeys of the participants and reveal their views, attitudes, and degrees of theoretical integration. These also demonstrate how their stories inform their conceptualizations, applications, and suggestions for developing multicultural social justice leadership.

Each author explains how to craft interventions and lead applications in a variety of contexts from a practitioner's point of view. In each of the cases the authors express a clear intent to affect specific contexts. All speak of ways to impact individuals, groups, or organizations and promote equality and justice.

We sincerely hope that this special issue will provide new insights about how to develop leadership that is respectful of multicultural variations and how to focus on actions to improve the lives of all members of our society. We also hope that the narratives in general and the specific demonstrations in particular, will become the seeds for more conversations and newer examples. Finally, we hope that the methodology experimented here will model a way to engage our brothers and sisters attending leadership presentations in a fruitful and transformative dialogical exchange.

We would like to express our deepest appreciation to each one of the contributors. Authors, participants, reviewers, academy chairs and journal editors shared their time, expertise, and enthusiasm with unflinching determination to make this special issue possible. We all share the responsibility for this issue. We all share the responsibility for providing novel readings to those interested in multicultural social justice leadership, and for giving support 
and education to those striving to become, or teach others to become, leaders that honor our ethical and professional call to remove barriers, advocate for those in need, and seek the changes that advance social justice.

The narratives, theoretical, and practical applications included here are in your hands. Use these to advance our knowledge and to provide newer insights and practices.

Read, reflect, share, and continue conversing ... .

Contact information/Correspondence:

Carlos P. Zalaquett, Ph.D., Guest Editor for the Special Issue

Department of Psychological and Social Foundations

University of South Florida

4202 E. Fowler Ave. - Stop EDU105

Tampa, FL 33620

Email: carlosz@usf.edu 